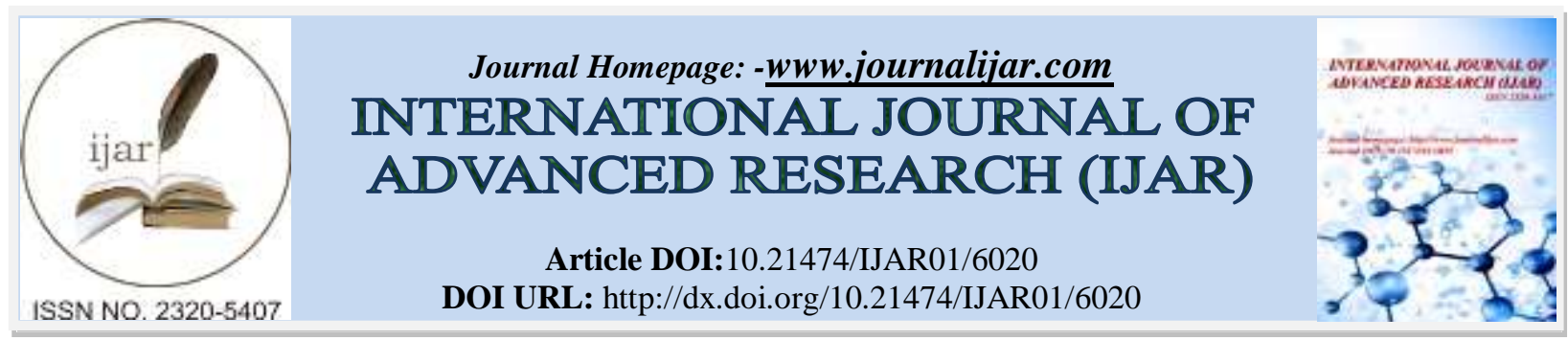

RESEARCH ARTICLE

\title{
EFFECT OF CURCUMA LONGA SUPPLEMENTATION ON LIPID PEROXIDATION, SERUM AMYLASE, LIPASE ACTIVITES IN MICE EXPOSED TO CADMIUM.
}

Suman Sharma and Anu.

Department of Zoology and Environmental Sciences, Punjabi University, Patiala - 147002, Punjab, India.

\section{Manuscript Info}

\section{Manuscript History}

Received: 10 October 2017

Final Accepted: 12 November 2017

Published: December 2017

Key words:-

Cadmium (Cd), Curcuma longa (Cur), malondialdehyde (MDA), $\alpha$ amylase, lipase.

\begin{abstract}
This study was designed to investigate the ameliorating effect of Curcuma longa (curcumin) against cadmium chloride toxicity in pancreatic tissue of mice. Twenty mice were divided into four equal groups. Group 1 was given distilled water orally and considered as control group, group 2 received $1 \mathrm{mg} / \mathrm{kg} \mathrm{B}$.w of cadmium chloride on alternate days, group 3 received $1 \mathrm{mg} / \mathrm{kg} \mathrm{B}$.w of cadmium chloride on alternate days and $100 \mathrm{mg} / \mathrm{kg}$ B.w of curcumin every day for 15 days, group 4 received $100 \mathrm{mg} / \mathrm{kg} \mathrm{B} . \mathrm{w}$ of only curcumin daily and were kept as positive control. Autopsies were done on 15 days post treatment. The results showed an adverse effect of cadmium on oxidative balance and serum enzymatic activities, while curcumin showed effective antioxidant effect which was shown by a decrease in MDA (lipid peroxidation), serum amylase and lipase concentration.
\end{abstract}

Copy Right, IJAR, 2017,. All rights reserved.

\section{Introduction:-}

Cadmium $(\mathrm{Cd})$ is an important industrial and environmental pollutant that currently ranks seventh on the ATSDR/EPA list of Hazardous Substances (ATSDR., 2002). The diverse deleterious health effects upon exposure to toxic heavy metals in the environment is a matter of serious concern and a global issue (Patra et al., 2011). Cadmium is an important environmental pollutant present in soil, water, air and food. Anthropogenic sources add 3-10 times more cadmium to the atmosphere than natural sources (Irwin et al., 2003). After the entry of cadmium in organism's body, it gets accumulated and has a very long biological half-life of 15-20 years (Son et al., 2011). Further its excretion rate is very low. Various animal studies have shown that $\mathrm{Cd}$ can cause pancreatic $\beta$-cell damage, suppress insulin secretion, increase glucose intolerance, and have diabetogenic effects (Han et al., 2003).

Besides food, cigarette smoke is the largest source of non-occupational exposure, because $\mathrm{Cd}$ tends to accumulate in tobacco leaves and between $40 \%$ and $60 \%$ of inhaled $\mathrm{Cd}$ can enter blood circulation. Cadmium content in cigarettes may vary with cigarette brand, but the usual content per cigarette ranges between $1 \mu \mathrm{g}$ and $2 \mu \mathrm{g}$. While the average person absorbs around $1 \mu \mathrm{g}$ of $\mathrm{Cd}$ through food per day, smokers that smoke one pack of cigarettes per day can absorb additional $1 \mu \mathrm{g}$ to $3 \mu \mathrm{g}$ of $\mathrm{Cd}$ and thus heavy smokers have more than double the Cd body content (ATSDR; 2008; Lewis et al., 1972).

Lipid peroxidation is the oxidative deterioration of lipids containing a number of carbon-carbon double bonds to form a lipid hydroperoxide (ROOH) which then react further (Devasagayam et al., 2003). Hydroperoxides are formed as the primary products in lipid

Corresponding Author :-Anu.

Address:-Department of Zoology and Environmental Sciences, Punjabi University, Patiala - 147002,

Punjab, India. 
peroxidation, they have toxic effects on cells and they may react with transition metals like iron or copper to form stable aldehyde such as Malondialdehyde (Maritim et al., 2003) which is a good marker of free radical-mediated damage, oxidative stress and a suitable biomarker for lipid peroxidation (Dauqan et al., 2011). Lipid peroxidation is now known as responsible for a number of diseases and clinical conditions including premature birth disorders, diabetes, Parkinson's disease, Alzheimer's disease, atherosclerosis, fibrosis, cancer, inflammatory liver injury and many others (Devasagayam et al., 2003). Malondialdehyde is mutagenic and carcinogenic (Valko et al., 2005) and can react with DNA bases and induce mutation (Marnett et al., 1999).

The various toxic effects induced by $\mathrm{Cd}$ in biological systems have been linked to increased lipid peroxidation, as an early and sensitive consequence of $\mathrm{Cd}$ exposure. The increase in lipid peroxidation due to Cd toxicity have been attributed to alterations in the antioxidant defense system which includes enzymes such as glutathione peroxidase (GPx), glutathione-S-transferase, superoxide dismutase (SOD) and catalase (CAT), and nonenzymatic molecule like glutathione, which normally protect against free radical toxicity (Patra et al., 1999).

Long-term exposure to $\mathrm{Cd}$ results in a marked increase in blood glucose and decrease in plasma insulin secretion that are associated with blood and urinary levels of $\mathrm{Cd}$ (Lei et al., 2007). Pancreatic $\beta$-cells are susceptible to oxidative stress damage, which is generated by chronic exposure to high levels of glucose and toxic agents causing pancreatic $\beta$-cell dysfunction and apoptosis (Chen et al., 2009; Azevedo et al., 2006).

Cadmium is known to affect carbohydrate metabolism by injuring the beta cells of Islets of Langerhans and reducing insulin secretion (Lei et al., 2005). Cd also leads to necrosis, degeneration and degranulation of beta cells, causing an increase in the serum glucose level (Kanter et al., 2003). Cadmium exposure stimulates lipid peroxidationinduced tissue damage (Medina et al., 2017). Amylase is a glycoside hydrolase involved in carbohydrate digestion. Lactate dehydrogenase is an oxidoreductase with important roles in carbohydrate metabolism; in mammals it has five main isoforms. Alkaline phosphatase is a hydrolase involved in dephosphorylation (Murray et al., 2003).

Phytochemicals occur naturally in plants. There has been considerable public and scientific interest in the use of phytochemicals. The dried rhizome of the perennial herb Curcuma longa Linn, known generally as turmeric in English and haldi in Hindi has been used in Asian medicine (Brouk, b., 1975). Its utility is referred in the ancient Hindu scripture, the Ayurveda. Curcumin has been used in traditional Indian medicine for centuries, and has numerous pharmacological activities, including potent anti-inflammatory, antioxidant, chemopreventive and chemotherapeutic actions (Hatcher et al., 2008). Curcumin also has a beneficial effect on blood glucose in diabetics and increases gastric mucosal secretion in rabbits (Nanda et al., 2002).

Curcumin (1,7-bis(4-hydroxy-3-methoxyphenyl)-1,6-heptadiene-3,5-dione), the active portion of turmeric, has been shown to have significant antioxidant activity, both in vitro and in vivo (Joe et al., 2004), curcumin is a potent scavenger of reactive oxygen and nitrogen species such as hydroxyl radicals and nitrogen dioxide radicals (Reddy and Lokesh, 1994).

The rhizomes of the Curcuma species are usually aromatic, carminative and are used to treat indigestion, hepatitis, jaundice, diabetes, atherosclerosis and bacterial infections (Van et al., 2004). They contain molecules credited with anti-inflammatory, antirheumatism, antimicrobial, antiviral, insect repellent, antidiabetic, hypocholestraemic, choleretic, antifibrotic, antivenomous and antihepatotoxic properties as well as anticancerous properties (Sasikumar, b., 2005).

Curcumin, a yellow coloring ingredient of the spice turmeric obtained from the rhizomes of Curcuma longa (Zingiberacea). Curcumin has various health-benefiting properties; anti-diabetic, Antioxidants, anti-inflammatory, anticarcinogenic, antiviral, hypolipidemic and anti-infectious (Miller et al., 2001; Aggarwalet al., 2003).

\section{Material and Methods:-}

Animals: In this study, 20 healthy mature male swiss albino mice weighing $20 \pm 2$ grams were used and purchased from the Central Research Institute, Kasuali. 20 mice were divided into four groups in which five animals were kept in each group ( 5 animals /cage). The animals were housed in well ventilated standard environmental conditions at temperature $25 \pm 2^{\circ} \mathrm{C}$ and 12 hours light/day for 15 days. Pellet diet (obtained from Hindustan Liver Limited, Mumbai, India) and tap water were given ad libitum. The animals were handled with human care in accordance with the guidelines of the Institutional Animal Ethical Committee. 
Procurement of chemicals:

Cadmium chloride $\left(\mathbf{C d C l}_{2}\right)$ and Curcumin powder:- were obtained from Himedia laboratories Pvt. Ltd. MUMBAI.

Experimental Design: Mice were divided into following 4 groups and 5 mice were kept in each group.

The first group:-

Served as control and they were provided standard pellet feed and tap water ad libitum.

The second group:-

Received cadmium chloride $\left(\mathrm{CdCl}_{2}\right)$ orally at a dose of $1 \mathrm{mg} / \mathrm{kg}$ body weight on alternate days for 15 days.

The third group:-

Administered an oral dose of $1 \mathrm{mg} / \mathrm{kg}$ body weight of $\mathrm{CdCl}_{2}$ on alternate days and $100 \mathrm{mg} / \mathrm{kg}$ body weight of curcumin orally daily for 15 days.

The fourth group:-

Was given $100 \mathrm{mg} / \mathrm{kg}$ body weight of curcumin daily for 15 days and were kept as positive control.

The mice were sacrificed on 15 days post treatment from each group.

Blood collection:-

Blood sample were collected from the retro orbital venous plexus of each mice and was collected in separate eppendrof tubes. The blood sample was centrifuged at $3000 \mathrm{rpm}$ at $4^{\circ} \mathrm{C}$ for 15 minutes and serum was then stored at $-20^{\circ} \mathrm{C}$ for later use for biochemical analysis.

\section{Tissue preparations:-}

Tissue homogenates of pancreas were prepared with the help of tissue homogenizer in $3 \mathrm{ml}$ of phosphate buffer ( $\mathrm{pH}$ 7.2) and used for estimation of lipid peroxidation which was measured as malondialdehyde a thiobarbutaric acid reacting substance, using the reported method of (Wilbur et al. 1949).

\section{Lipase and $\alpha$ - Amylase assay:-}

Lipase and $\alpha$-Amylase were assayed using commercially available kits from AGAPPE DIAGNOSTICS LTD and RECKON DIAGNOSTICS P.LTD (INDIA) respectively according to manufacturer's instructions.

Statistical analysis:-

The data was analyzed by using unpaired Student's $t$-test. The $\mathrm{p}$ value $<0.05$ was considered statistically significant.

\section{Result And Discussion:-}

Results showed that administration of cadmium significantly enhanced MDA level $(\mathrm{p}<0.05)$ and treatment with curcumin and $\mathrm{CdCl}_{2}$ exposed group did significantly improved MDA level as compared to control group ( $\mathrm{p}<0.05$ ). No significant change in only curcumin treated group was observed (p>0.05) (Fig. 1).

Cadmium exposure in this study significantly increased Serum amylase $(\mathrm{p}<0.001)$. The mice treated with cadmium and curcumin showed significant decrease in amylase activity as compare to control group ( $<<0.01)$. But no significant change in amylase activity was observed in only curcumin treated group (p>0.05) (Fig. 2).

A significant increase $(\mathrm{p}<0.01)$ in lipase activity was observed which indicated that the amount of lipase is adversely affected by cadmium and supplementation with curcumin against cadmium exposed group showed significantly decrease in lipase activity $(\mathrm{p}<0.05)$ as compared to control group. No significant changes were observed in only curcumin exposed group ( $p>0.05$ ) (Fig. 3). These mice thus showed protection afforded by curcumin. 


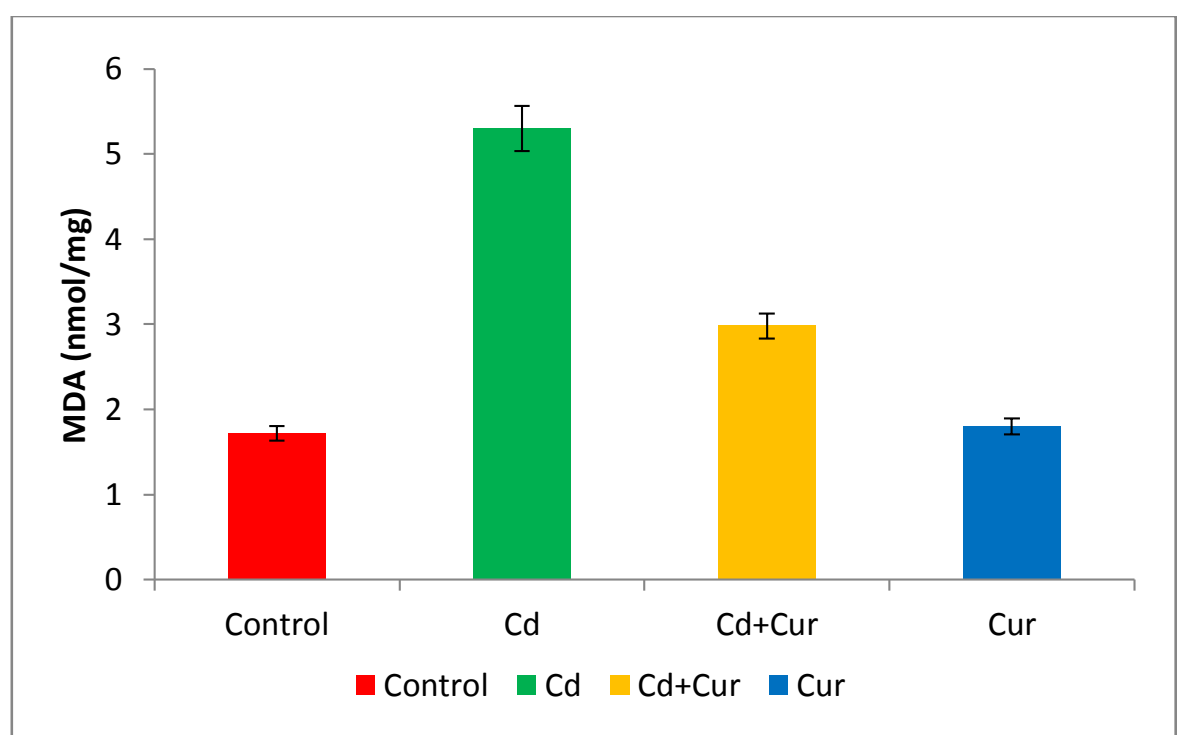

Fig. 1:-MDA activity: Cadmium exposed group showing significant increase in MDA $(\mathrm{p}<0.05)$ and curcumin and cadmium exposed group showing significant decrease in MDA $(\mathrm{p}<0.05)$ as compared to control.

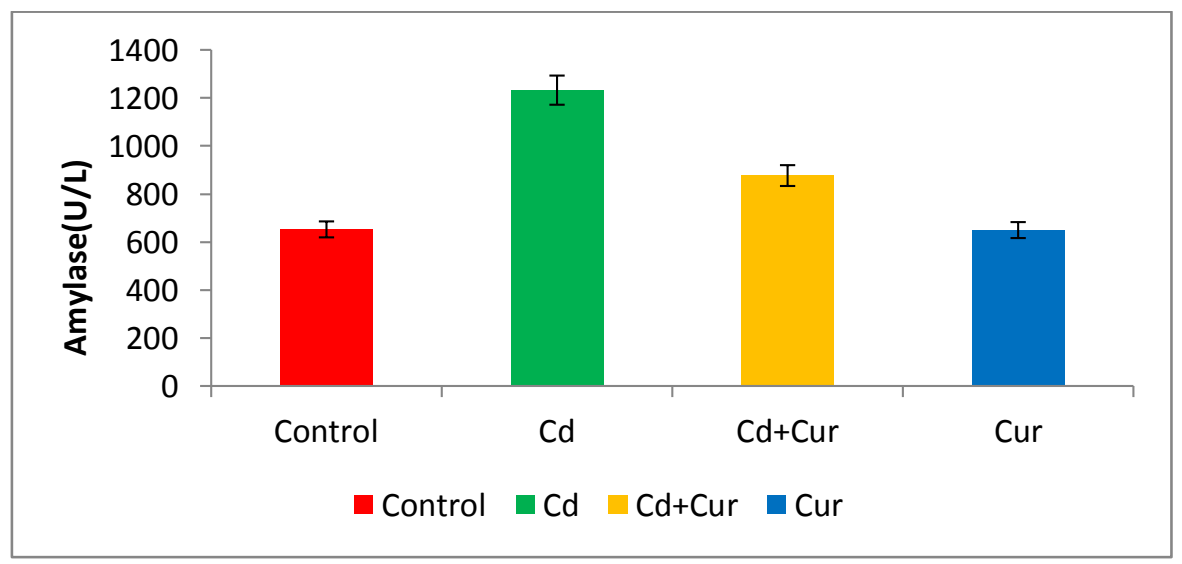

Fig. 2:-Amylase activity: Cadmium exposed group showing increase in amylase significantly $(\mathrm{p}<0.001)$ and curcumin and cadmium exposed group showing significant decrease in amylase $(\mathrm{p}<0.01)$ as compared to control.

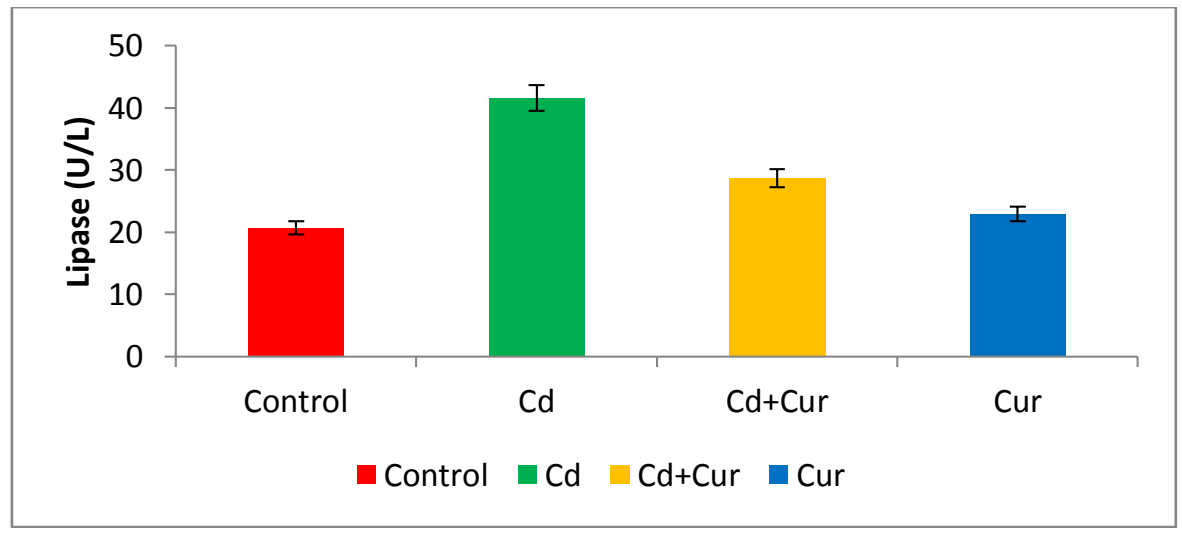

Fig. 3:-Lipase activity: Cadmium exposed group showing increase in lipase significantly $(\mathrm{p}<0.01)$ and curcumin and cadmium exposed group showing significantly decrease in lipase $(\mathrm{p}<0.05)$ as compared to control. 
The present study showed that cadmium increases the MDA level in pancreas. Similar results were observed by (Chang et al., 2013) and they observed that cadmium also increased intracellular reactive oxygen species (ROS) generation and malondialdehyde (MDA) production and induced mitochondrial dysfunction in pancreatic $\beta$-cells.

Cadmium is one of the heavy metals, which is characterized as one of the most toxic, carcinogenic, teratogenic, mutagenic environmental and industrial pollutant (Cijauskaite et al., 2014). It is responsible for causing damage in kidneys, liver, lung, pancreas, testes, placenta, bone and producing oxidative stress (Cuypers et al., 2010). Cadmium stimulates free radical production, therefore cell oxidant-antioxidant balance is disturbed. It leads to oxidative deterioration of lipids, proteins and DNA in various tissue cells (Cuypers et al., 2010, Bernhoft et al., 2013, Cijauskaite et al., 2014). Lipid peroxidation is caused by reactive oxygen species, also known as free radicals, which attacks double bonds in unsaturated membrane lipids. Therefore, lipid peroxidation leads to cell membrane damage (Marisa et al., 2012). Aerobic organisms can control lipid peroxidation process by using antioxidative system. It consists of antioxidative enzymes and low molecular weight substances which are capable to reduce free radicals concentration in cells (Bartikova et al., 2015).

Evans et al., (2003) and Robertson, (2006) also suggested that the pancreas may be more susceptible to oxidative stress than other tissues and organs, because pancreatic islet cells show extremely weak manifestation of antioxidant enzymes. Lipid peroxidation decreases the membrane fluidity, changes the phase properties of the membranes and decreases electrical resistance (Rice et al., 1993).

In present study an increase in amylase and lipase activity was observed with cadmium toxicity. Khorasgani et al., (2013) also evaluated that cadmium exposure significantly enhanced serum amylase and lipase as compared to control. Cadmium administered through the drinking water for 26 weeks to rats caused a slight increase in serum amylase (Lukacinova et al., 2012).

Acute pancreatitis due to cadmium is followed by increased level of plasma amylase and lipase (Shimada et al., 2000). Pancreas of rats exposed to cadmium showed signs of inflammation and degenerative and necrotic changes. Similarly Kanter et al., (2003) also reported that cadmium exposure could induce necrosis, degeneration and degranulation in beta-cells of pancreatic islets.

It has been reported that curcumin scavenges oxygen free radicals and inhibits lipid peroxidation and protects cellular macromolecules, including DNA from oxidative damage (Kalpana and Menon, 2004; Polasa et al., 2004). It is known to be a multi-functional agent, such as powerful anti-oxidant, antidiabetic, anti inflammatory and anticancer agent (Miller et al., 2001).

In present study there is decline in MDA, serum amylase and lipase activity when protection of curcumin is given in cadmium treated group as compared to control group. Serum amylase and lipase levels are most commonly used as biochemical markers of pancreatic disease, particularly acute pancreatitis. (Panteghini et al., 1993; and Seo et al., 2010). In this study administration of Curcuma longa significantly reduced the serum amylase and lipase levels. Similar results with curcumin was also reported by Aziz et al., (2012) and showed that water soluble curcumin derivative significantly decreased the levels of MDA in the pancreas, liver and aorta. Meanwhile, the same treatment showed non-significant decrease in MDA levels in the respective tissues of the water soluble curcumin derivative control group.

Conclusion:-Curcumin supplementation alleviated cadmium induced changes in serum amylase, lipase and MDA activity when compared to cadmium alone or control group. No harmful effects of curcumin were observed in only curcumin treated group and no changes were found in the concentration of MDA as well as in the activity of serum amylase and lipase of these mice as compared to control group in the present study.

\section{Acknowledgement:-}

The authors gratefully acknowledge the Department of Zoology \& Environmental Sciences, Punjabi University, Patiala, for providing the necessary facilities to pursue the research work. 


\section{References:-}

1. Agency for Toxic Substances and Disease Registry website. (2002): Available at: http://www.atsdr.cdc.gov/cxcx3.html.ATSDR.

2. Agency for Toxic Substances and Disease Registry. (2008): Toxicological profile for cadmium. Atlanta (USA): ATSDR.

3. Aggarwal, B. B., Kumar, A. and Bharti, A. C. (2003): Anticancer potential of curcumin: preclinical and clinical studies. Anticancer Res, 23: 363-398.

4. Azevedo-Martins, A. K., Monteiro, A. P., Lima, C. L., Lenzen, S. and Curi, R. (2006): Fatty acid-induced toxicity and neutral lipid accumulation in insulin-producing RINm5F cells.Toxicol, 20: 1106-1113.

5. Bártíková, H., et al. (2015): Effect of oral administration of green tea extract in various dosage schemes on oxidative stress status of mice in vivo. ActaPharmaceutica, 65(1): 65-73.

6. Bernhoft, R.A. (2013): Cadmium toxicity and treatment. Sci. World J.

7. Brouk, B. (1975): Plants Consumed by Man. New York: Academic Press. 331.

8. Chang, K.C., Hsu C.C., Liu S.H., Su C.C., Yen C.C., et al. (2013): Cadmium Induces Apoptosis in Pancreatic $\beta$-Cells through a Mitochondria-Dependent Pathway: The Role of Oxidative Stress-Mediated c-Jun N- Terminal Kinase Activation. PLOS ONE. 8(2).

9. Chen, Y. W., Yang, C. Y., Huang, C. F., Hung, D. Z. and Leung, Y. M. (2009): Heavy metals, Collins, Colorado contaminants encyclopedia, National Park Service, Water Resources Division, Fort.

10. Čijauskaite, K., Bernotienè, R., Ivanov, L. (2014): Influence of cadmium ions on the reduced glutathione and lipid peroxidation in the liver and red blood cells of mice. Biologija, 59(4).

11. Cuypers, A., et al. (2010): Cadmium stress: an oxidative challenge. Biometals, 23(5): 927-940.

12. Dauqan, E. M. A., Abdullah, A. and Sani, H. A. (2011): Natural antioxidants, lipid profile, lipid peroxidation, antioxidant enzymes of different vegetable oils. Adv J Food SciTechnol, 3(4): 308-316.

13. Devasagayam, T. P. A., Boloor, K. K. and Ramasarma, T. (2003): Methods for estimating lipid peroxidation: an analysis of merits and demerits. Indian J. Biochem. Biophys, 40: 300-308.

14. Evans, J. L., Goldfine, I.D., Maddux, B. A., Grodsky, G. M. (2003): Are oxidative stress-activated signaling pathways mediators of insulin resistance and beta-cell dysfunction? Diabetes, 52 (1): 1-8.

15. Han, J. C., Park, S. Y., Hah, B. G., Choi, G. H. and Kim, Y. K. (2003): Cadmium induces impaired glucose tolerance in rat by down-regulating GLUT4 expression in adipocytes. Arch Biochem Biophys, 413: 213-220.

16. Hatcher, H., Planalp, R., Cho, J., Torti, F. M. and Torti, S. V. (2008): Curcumin: from ancient medicine to current clinical trials. Cell. Mol. Life Sci, 65: 1631-1652.

17. Irwin, R. J., Mouwerik, M. V., Stevend, L., Seese, M. D. and Basham, W. (2003): Environmental islet function and diabetes development. Toxicol, 1: 169-176.

18. Joe, B., Vijaykumar, M., Lokesh, B.R., (2004): Biological properties of curcumin-cellular and molecular mechanisms of action. Crit. Rev. Food Sci. Nutr, 44: 97-111.

19. Kalpana, C. and Menon, V.P. (2004): Curcumin ameliorates oxidative stress during nicotine induced lung toxicity in Wistar rats. Italian J. Biochem, 53: 82-86.

20. Kanter, M., Yoruk, M., Koc, A., Meral, I. and Karaca, T. (2003): Effects of cadmium exposure on morphological aspects of pancreas, weights of fetus and placenta in streptozotocin- induced diabetic pregnant rats. Biol. Trace Elem. Res, 93(1-3): 189-200.

21. Khorasgani, E. L., Haghdoost, I. S., Sedaghat, R., Mortazavi, P. and Roghani, M. (2013): Satureja hortensis L. Alcoholic extract ameliorates cadmium induced pancreatic damage in rats. Middle East J Sci Res, 15(1): 32-35.

22. Lei, L. J., Jin, T. Y. and Zhou, Y. F. (2005): The toxic effects of cadmium on pancreas. Biomed Environ Sci, 23(1): 45-9.

23. Lei, L. J., Jin, T. Y. and Zhou, Y. F. (2007): Insulin expression in rats exposed to cadmium. Biomed Environ Sci, 20(4): 295-301.

24. Lewis, G. P., Coughlin, L. L., Jusko, W. J. and Hartz, S. (1972): Contribution of Cigarette smoking to cadmium accumulation in man. Lancet, 299: 291-299.

25. Lukacinova, A., Novakova, J., Lovasova, E., Cimbolakova, I., Nistar, F. (2012): - Influence of lifetime exposure of sublethal doses of cadmium to selected parameters of carbohydrate metabolism. Potravinarstvo, 6(4): 36-40.

26. Marisa, R., Boveris, A., and Semprine, J. (2012): Lipid peroxidation: chemical mechanism, biological implications and analytical determination. INTECH Open Access Publisher.

27. Maritim, A. C., Sanders, R. A. and Watkins, J. B. (2003): Diabetes, oxidative stress and antioxidants: A review. J Biochem Mol Toxicol, (1): 24-38. 
28. Marnett, L. J. (1999): Lipid peroxidation-DNA damage by malondialdehyde. Mutat Res- Fundamental and Molecular Mechanisms of Mutagenesis. 424: 83-95.

29. Medina, M. F., Arrieta, M. C., Villafañe, M. N., Klyver, S. M. R., Odstrcil, I. M. A., González, M. E., (2017): Early signs of toxicity in testes and sperm of rats exposed to low cadmium doses. Toxicol, Ind. Health.

30. Miller, J. S. M., Angeles, F. M., Reuter, B. K., Bobrowski, P. and Sandoval, M. (2001): Dietary antioxidants protect gut epithelial cells from oxidant-induced apoptosis. BMC Complement. Altern. Med, 1: 11.

31. Mohamed, T. Abdel Aziz1., Mohamed, F. El-Asmar., Ibrahim, N. El-Ibrashy., Ameen, M. Rezq., Abdulrahman, L. Al-Malki., Mohamed, A. Wassef., Hanan, H. Fouad., Hanan, H. Ahmed., Fatma, M. Taha., Amira, A. Hassouna and Heba, M. Morsi. (2012): Effect of novel water soluble curcumin derivative on experimental type1 diabetes mellitus (short term study). Diabetes Metab Syndr, 4: 30.

32. Murray, R. K., Granner D. K., Mayers P. A., Rodwell V. W. (2003): Harper's illustrated Biochemistry $26^{\text {th }}$ ed. $^{2}$ Lange McGrew-Hill, New York, USA.

33. Nanda, A. and Gupta, N. (2002): Efficacy of turmeric on blood glucose and polyol pathway in diabetic albino rats. Plant Foods Hum Nutr, 57: 41-52.

34. Panteghini, M., Pagani, F. and Bonora, R. (1993): Clinical and analytical evaluation of a continuous enzymatic method for measuring pancreatic lipase activity. Clin Chem, 39: 304-308.

35. Patra, R. C., Swarup, D. and Senapat, S. K. (1999): Effects of cadmium on lipid peroxides and superoxide dismutase in hepatic, renal and testicular tissue of rats. Vet. Human Toxicol, 41(2): 65-67.

36. Patra, R. C., Rautray, A. K. and Swarup, D. (2011): Oxidative stress in lead and cadmium toxicity and its amelioration. Vet Med Int, 1-9.

37. Polasa, K., Naidu, N.A., Ravindranath, I., Krishanaswamy, K., (2004): Inhibition of B(a)P induced strand breaks in presence of curcumin. Mutat. Res, 557: 203-213.

38. Reddy, A. C., Lokesh, B. R., (1994): Studies on the inhibitory effects of curcumin and eugenol on the formation of reactive oxygen species and the oxidation of ferrous iron. Mol. Cell. Biochem, 137: 1-8.

39. Rice-Evans, C., Burdon, R. (1993): Free radical-lipid interactions and their pathological consequences.-Progr. Lipid Res, 32: 71-110.

40. Robertson, R. P., (2006): Oxidative stress and impaired insulin secretion in type 2 diabetes. Curr. Opin. Pharmacol, 6 (6): 615-619.

41. Sasikumar, B. (2005): Genetic resources of Curcuma: diversity, characterization and utilization Plant Genet. Resour, 3: 230-251.

42. Seo, K.I., Myung-Sook, C., Jung Un, Ju.,Hye-Jin, Kim, Jiyoung, Y., Seon-Min, Jeon., Mi-Kyung, Lee., (2008): Effect of curcumin supplementation on blood glucose, plasma insulin, and glucose homeostasis related enzyme activities in diabetic mice. Mol. Nutr. Food Res, 52 (9): 995-1004.

43. Shimada, H., Funakoshi, T. and Waalkes, M. P. (2000): Acute, nontoxic cadmium exposure inhibits pancreatic protease activities in the mouse. Toxicol Sci, 53: 474- 480.

44. Son, Y. O., Wang, X., Hitron, J. A., Zhang, Z., Cheng, S. P., Budhraja, A., Ding, S. Z., Lee, J. C. and Shi, X. L. (2011): Cadmium induces autophagy through ROS- dependent activation of the LKBI-AMPK signaling in skin epidermal cells. Toxicol Appl Pharmacol, 225: 287-296.

45. Valko, M., Morris, H. and Cronin, M. T. D. (2005): Metals, toxicity and oxidative stress. Curr Med Chem, 12: 1161-1208.

46. Van, W. B. E. and Wink M. (2004): Medicinal plants of the world Portland. Timber press, 118.

47. Wilbur, K. M., Bernheim, F. and Shapiro, O. W. (1949): The thiobarbituric acid reagent as a test for oxidation of unsaturated fatty acids by various agents. J Biochem Biophys, 24: 305-313. 